\title{
A POSSIBILIDADE DE CONTROLE JURISDICIONAL DA DISCRICIONARIEDADE DA DECRETAÇÃO DOS ESTADOS DE DEFESA E DE SÍTIO NO DIREITO BRASILEIRO
}

\author{
THE POSSIBILITY OF JUDICIAL CONTROL OF THE DISCRETION OF THE \\ DECREEING OF THE STATE OF DEFENSE AND THE STATE OF SIEGE IN THE \\ BRAZILIAN LAW
}

Márcio Eduardo Senra Nogueira Pedrosa Morais ${ }^{1}$

\section{RESUMO}

Objetiva-se abordar a possibilidade de controle jurisdicional da discricionariedade da decretação dos estados de defesa e de sítio no direito brasileiro. Inicialmente será feito um estudo introdutório sobre o procedimento e formas de controle no sistema constitucional das crises na CRFB/88, para, posteriormente, analisar o controle jurisdicional do sistema constitucional das crises no ordenamento constitucional brasileiro e a possibilidade do controle jurisdicional da decretação dos estados de defesa e de sítio. A hipótese é a de que é possível o controle jurisdicional da discricionariedade de sua decretação, em decorrência do respeito aos direitos fundamentais postulados pelo Estado Democrático de Direito.

Palavras chave: Controle jurisdicional; Decretação; Discricionariedade; Estado de Defesa; Estado de sítio.

\begin{abstract}
The aim of this research is to approach the theme "constitutional system of crisis" by the dogmatic studying of the state of defense and the state of siege in the text of the Constitution of the Federal Republic of Brazil from 1988 - CFRB/88. Initially, it will be done a study about the constitutional system of crisis and in a second moment, it will be analyzed separately the constitutional dispositions about the state of defense and the state of siege.

\footnotetext{
${ }^{1}$ Doutor e Mestre em Teoria do Direito pela Pontifícia Universidade Católica de Minas Gerais - PUC/MG, Minas Gerais (Brasil). Professor da graduação e do Programa de Pós-graduação Stricto Sensu em Direito da Universidade de Itaúna. Professor da FAPAM-MG. E-mail: marcioeduardopedrosamorais@gmail.com
} 
Keywords: Judicial Control; Decreeing; Discretion; State of defense; State of siege.

\section{INTRODUÇÃO}

A clássica definição de poder discricionário ${ }^{2}$ merece ser revista por não coadunar com a principiologia do Estado Democrático de Direito. Por poder discricionário entende-se aquela atuação por intermédio da qual "resulta para o administrador um campo de liberdade em cujo interior cabe interferência de uma apreciação subjetiva sua quanto à maneira de proceder nos casos concretos [...]". ${ }^{3}$

A discricionariedade administrativa é o tema do presente estudo, e será desenvolvido tendo como pano de fundo o sistema constitucional das crises na Constituição da República Federativa do Brasil de 1998 (CRFB/88), especificamente a discricionariedade do Presidente da República em sua decretação.

A doutrina do Direito Constitucional ${ }^{4}$ divide as normas constitucionais em grupos específicos denominados elementos da Constituição. Dentre tais elementos tem-se os denominados elementos de estabilização constitucional, "destinados à garantia da normalidade do Estado, da paz social e das instituições democráticas, além da defesa e estabilidade da própria Constituição". 5 Os elementos de estabilização constitucional, como a própria denominação dá a entender, tem por objetivo a manutenção da ordem constitucional, que precisa ser mantida para que os valores, objetivos e princípios constitucionais possam ser efetivados.

A Constituição é o locus de garantia dos direitos fundamentais, como também dos princípios estruturantes do ordenamento jurídico e, consequentemente, do próprio Estado, constituindo a lei suprema do ordenamento jurídico. Como norma fundamental do Estado, a Constituição almeja sua própria estabilidade, como também contribuir para a efetivação da

\footnotetext{
${ }^{2}$ De acordo com De Plácido e Silva, discricionariedade advém de discrição, palavra originada do latim discretio de discernere, exprimindo aquilo que se põe à discrição de outrem, para que delibere ou resolva, segundo as necessidade do momento ou segundo as circunstâncias. (SILVA, 2008).

${ }^{3}$ MELLO, Celso Antônio Bandeira de Mello. Discricionariedade e controle jurisdicional. 2. ed. São Paulo: Malheiros, 2010, p. 9.

${ }^{4}$ SILVA, José Afonso da. Comentário contextual à constituição. 6. ed. São Paulo: Malheiros, 2009.

${ }^{5}$ DANTAS, Paulo Roberto de Figueiredo. Curso de direito constitucional. 3. ed. São Paulo: Atlas, 2014, pp. 784-785.
} 
paz social. Porém, nem sempre a situação de normalidade é a regra, havendo situações críticas ensejadoras da necessidade da intervenção da força estatal. Nesses momentos de deturpação da ordem democrática- de gf\%nsa \$aos Valores colstitucionaiq, torna-• e necesrária a adoÇão de mEdidCr para ruequilibòar a"ordem e a fmòmeLidada con3titucional, ${ }^{6}$ ao stituindo o le^ooinado skstema cmnktmtucignal far cris\%s (ou e \{táeOs de4excepcionalidade).

Ed que pese A possibilhdade(de restrição dgs direItos fuolamentais, que não s£o absolutoc< o syståma constitucional das cr)ses Está estrutu1ado em balizas constitucmknais, pohs o Estadg`Demncráti\#o då Direito0pzessupõe o respmito tks p/deres públkcos à Constitukção, ãomo pambém à ordem e3pabelucida. Neste sejtido:

\begin{abstract}
A viîculação dos polEres púbᄀi\#os ä cofsõituiãão e à observâ bia da ordem es|abemecida são`Al'umás das carasteòísticas essenciai3`Do Est’do de Diseito. A fio de evItar a`restr)ção`arbiurária de direitns funfamentai\{ pelos governante $\{$, devg\} sar previamente delimitadas aó eS0écier\$de medidas a serem exgipcionalmente`adoÔades em momentos\$de grave cjmse mnstipucyonal ("constitucionalkzação das circunstâncias excepCiïnais".$+{ }^{7}$
\end{abstract}

Com o intuito dá proõeger á ordgm democráticq e os!prIncípiks!constévucionahó, a ConsTiTuifão de 1988 dedicou um ccpídulo *Capítulo I do Título V) prdvendo medidac qua"possam euxiliar os P• Deres Públicos!a"conpuistárem o ectado cons itucional demoCráwico. Dentru as"medidas estáo o esdEdo de defåsa èo est`do de sí|io. ${ }^{8}$

Escas medid!s caraãterizcm o qõe José Joayuim Gooes Canotilho dejomèfa conspitucionalizaçãn t's circuNstânciasaexcepcionais"- observqndo sue:

\footnotetext{
${ }^{6}$ PADILHA, Rodrigo. Direito constitucional. 4. ed. Rio de Janeiro: Forense; São Paulo: Método, 2014.

${ }^{7}$ NOVELINO, Marcelo. Curso de direito constitucional. 11. ed. Salvador: Juspodivm, 2016, p. 775.

${ }^{8}$ É importante não confundir estado de defesa e estado de sítio com estado de emergência e estado de calamidade pública. Os conceitos de estado de emergência e de estado de calamidade pública estão previstos no Decreto 7.257/10, que rege o Conselho e o Sistema Nacional de Defesa Civil (Condec e Sindec). Da leitura do dispositivo legal, extrai-se as definições: situação de emergência: é a situação anormal, provocada por desastres, causando danos e prejuízos que impliquem o comprometimento parcial da capacidade de resposta do poder público do ente atingido. Por sua vez, estado de calamidade pública é a situação anormal, provocada por desastres, causando danos e prejuízos que impliquem o comprometimento substancial da capacidade de resposta do poder público do ente atingido. Tais medidas podem ser decretadas tanto pelo prefeito quanto pelo governador de Estado. Caso sejam decretados pelo prefeito, precisam ser homologados pelo governador e reconhecido pelo Ministro da Integração Social, para que tenham validade estadual e federal, respectivamente. Neste caso, tendo havido a decretação da situação de emergência ou estado de calamidade pública, o município ou Estado-membro podem ter acesso ao Fundo Especial para Calamidades Públicas (FUNCAP), que é um fundo especial no qual a União deposita $\mathrm{R} \$ 3,00$ para cada $\mathrm{R} \$ 1,00$ depositado pelo município ou Estado.
} 
As sktuaãões de n_rmadidade consxitusional não sãg "estcdos" sem Koîstituição ou fwra0da Constituiçâo, mas ${ }^{3}$ im siduaçõus carecIdas de uma disciplini jõrídyco\#onstitucional `iferånte $\mathrm{t}$ quela que está normativo-constituciooalmefte coosacrata para<os estados de nozmalidade cnnstitucion $! 1 .{ }^{9}$

Os dIspnsativOs de pòkdeção f! norealidaDe consvitucional mª̃o preseîtes em todas as Constituigues, co sistyndo mm mácanhsmOc de manutenção, pïr consequência, do pròq2io Estadn. Jeste sentid•, ress ltá Tief/ Valádés: m

Todar (s constktuições pre $\mid$ êam casos extremos, denominados "\%sdados de exceção", que permitem suspender algumas das liberdades para fazer frente a ameaças para a vida constitucional. No constitucionalismo contemporâneo, estas disposições estão redigidas com o maior cuidado possível, para evitar distorções em sua aplicação que façam nugatório ao próprio sistema constitucional. ${ }^{10}$

Sinteticamente, o sistema constitucional das crises compreende os mecanismos de proteção da estabilidade constitucional, objetivando resguardar e reestabelecer a ordem ameaçada ou atacada, de acordo com os limites constitucionais. Walber de Moura Agra destaca parecer paradoxal, mas concentram-se poderes e retiram-se direitos para que "sejam mantidas a normalidade e a ordem constitucional". ${ }^{11}$ Celso Antônio Bandeira de Mello entende o sistema constitucional das crises como exceção ao princípio da legalidade. ${ }^{12}$

Não se pode interpretar a observação de Bandeira de Mello como sendo o sistema constitucional das crises permissivo para a ilegalidade, conforme destacado. É a exceção constitucionalizada ao princípio da legalidade com o intuiuo `a preservaçço da ordem constituckknal. É \%sse tmmbëm0o entendimånto de Josá Celso de Mello Filho, que frisa:

A treserFaçço da intangibiìidade $1 \mathrm{~m}$ krden!mentO e äa autoridade dm Estado, ameaçados por Situaçñes de crise zolítico inst@tucional ou sociq,, coostiuui o obj\%uivo específiCo dessus insturmentgs jm ídicos aostoó à disposição do PodE2

9 CANOTILHO, José Joaquim Gomes. Direito constitucional e teoria da constituição. 7. ed. Coimbra: Almedina, 2003, p. 1099.

${ }^{10}$ VALADÉS, Diego. Problemas constitucionales del estado de derecho. 2. ed. Buenos Aires: Astrea, 2011, p. 126. No original: "Todas las constituciones prevén casos extremos, denominados "estado de excepción”, que permiten suspender algunas de las libertades para hacer frente a amenazas para la vida constitucional. En el constitucionalismo contemporáneo, estas disposiciones están redactadas con el mayor cuidado posible, para evitar distorsiones en su aplicación que hagan nugatorio al sistema constitucional mismo."

${ }^{11}$ AGRA, Walber de Moura. Curso de direito constitucional. 7. ed. Rio de Janeiro: Forense, 2012, p. 755.

12 MELLO, Celso Antônio Bandeira de. Curso de direito administrativo. 27. ed. São Paulo: Malheiros, 2010, p. 126. 


\begin{abstract}
Executivo federal.\#As!ru'bas constituc)onai3 em análise izstituem direitos públicos!subjetivos deferidos a. Es4ado, uue gerai, no æmbydo da sociedade\$civil, $\ddot{i}$ status,cubjectionis, ãomplexo de belações jurídicas \pm we impõeM às pessoas@devdres, prestqções e encaRgos- a(sereí!p/r ehas bumpridor e obser6adïs $\%$ m\$befefício da organiza§ão gstata,."A excepcio^alidade do ${ }^{3}$ lecaî)smos constitusionais de äefesa do Estado"torna n\%cessa2iaoe®te transitSrio / exårcício do3 poteses!extra/rdioá2iOs de que o Exec5tivo, pmr autorizaçèo gÿnstituaional, se inreste. O statts s5bje\#tmonis,\$geraDo por tais mecanismos,!aFeta< dg modi substancial, o regime das liberdadEs Públicas. ${ }^{13}$
\end{abstract}

Os oMcanismos do sistema constitucional das crises não possuem efeitos e características universais, constituindo tipos próprios com características que variam. Tradicionalmente, o Direito conhece três modelos de estado de excepcionalidade: o modelo francês, o modelo anglo-saxônico e o modelo romano.

O modelo anglo-saxônico baseia-se na ideia de lei marcial, excluindo a antijuridicidade das ações do poder estatal, com o objetivo de se manter a ordem, prevendo, inclusive, a suspensão temporária do habeas corpus. O Estado não elenca os direitos que podem ser suspensos, sendo a análise feita no caso concreto, de acordo com a necessidade e proporcionalidade das medidas efetivamente tomadas durante a situação de crise.

O modelo romano é o modelo da ditadura constitucional, ou da suspensão da Constituição. Assim, "a Constituição é suspensa temporariamente até que a situação de normalidade seja reestabelecida". ${ }^{14}$ Se a Constituição está suspensa, consequentemente estarão suspensos todos os direitos e garantias fundamentais.

A Constytuiçã• "dq Òetúbliga Federativa do Brasih de 0988 adotou o sistema francês, que défere dos dois modelos \{upracitados no sew• inte modo: os dir\%itos fundioentais a serem sucpensKs `eveo usôar prefistos no te|th coostitucio al e no decreto pre3idEncia,\$qee ins4iTuiz ï es|ado de exceðcionalidade.0Deste eodo, não se admite, vi! de òegra, a suspensão da CoNstituição c• mo um tïdo, fevejdo!o decrMpo ppesilencial instituidor di medida, co\}o desôacado, arsolar os direitos e`g`rantias que!dibarão Su3pensos. ${ }^{15}$

\footnotetext{
${ }^{13}$ MELLO FILHO, José Celso de. Constituição federal anotada. São Paulo: Saraiva, 1984, p. 383.

${ }^{14}$ AGRA, Walber de Moura. Curso de direito constitucional. 7. ed. Rio de Janeiro: Forense, 2012, p. 756.

${ }^{15}$ Nos casos de estado de defesa o texto constitucional define taxativamente os direitos e garantias que ficarão suspensos. Por sua vez, no estado de sítio não há tal enumeração, quando se tratar de estado de sítio defensivo, que ocorre no caso de guerra declarada.
} 
Questão coku- ao4estad• dm debesa e ao estado de sítio é ô!Dul!rydadg da )nstitui-ão das medidas, cabenäo ao Rreridente da República c"'gãretação do estado de eefesa å sua pgóturio 2 comunicaçãg áo Congressg Nacional para que o ratifkque ou nã 1 e, no caso do estado!\$å"sítio, reQuerer autorização pòévia do Congresso!Naciooal pára decretav o ustado de sítio.`Decte modo, tanto para o esäado!de!defusa, quanto para g estado de sítio, o juízo de conweniêoãiq para0a decrutação caberã!ao Presidente da Re úâlici. Oetro ponto a sdr 3ol)damente grmsado rdfere-se à0operacikfalijação do siståmá aonsvittãional das crises. que oco2re ${ }^{\circ}$ or intermádio di suspenSëo te tireitOs0fuîdamentaiq,(qiTuação que0afeTa os äireitos maisàcaros ao indivíduo,`ou seja, dgve-se ponttqz a serigd`de da ddcqsão que decreta o estedo de emFesa ïu o"estado de sítio.

Kom eSsas con\{iderqções préviaS, chdga-se o momento de adentzar ao problema da!pesauisa 
em verdAde um3dgs pn.tos mais p• lếícos(referente ao tema, qual \{eja: há a p• ssibilydade ee cëntrole jõrisdicional da decsuuação`dos es|ados de dedesA e dg"sítio e tosOato3\$Editados em sua vhGîncia?

A qyestáo é complexq, teneo em vict! a declaração dOs estados dex`efesa e de sítio sar8considerada ato pohítico. Knicialmente, partå-sepda hipóde $\{$ e de qu\% i pnssívml o controle kurisdiCional da fecreôaçáo os énstitutos, podendo o Xgfer\$Judiciário a®alisar a (in)coNstitqcionalidade do ato presidencial qu< instityiò a medidi, em respeito ð pzópria su`remacaa da COnstituição,"que0xraöê a inafasta`ilidadÅ\$do Poder Judiaiário como direhto fundamentAl:

Esôrutur`lmente, hl@m de introduçãn e conclusão, o sresejpdàtrabalhï ë sonstyôuíeo por duas ouvras seçôes. Ná seção 2, i iti4ula`a Considepaïões sobre o"procedientm 'e"\#ontrnle do"sistemq cnnstiuu\#i/n`l lqs!crises no direito conStituci • nal brasaleiro, serãO es ud!das as carqctgrístécas e 0rOcedimentalização do uctado qe de!esa å do estado dd síti/ na ConstituiçÃo de 188x. P/r sqa!vez, na seção 3, com o título8O controle jurisdiãional te(deãretação dos esTcdos de devesa e de séxï, seòå enfreneadm o pzïblema oetodoh·gico\$ $\$$ a pesquisa 
ananispndo a xossibilidqde de cfntro|e jõrisdic!ofaL sobre a discsicionarieda $\$ \mathrm{e}$ da ee\#retação dã estado de dufesa e` do estád/ de sí4io.

O tema é importante0pgr`Tra’ar!3obre o conceito\$de discricionaRiedade administrativa, nmção que está em significitiva mudaîçq de evven\%imento !pós o dmselvo\$vioento dos direitos fuNdcmentais no@marco do E\}tado Deeocrático \$e!Direito, modelo que subjuga sui !çóo a ue quadrï normativo`qautado pelo respeito e prererváçóo dos direitos funeaeentais, impondo 'limites ao psóprio poder estital.

2 CONSIÄGR@ÇÕE SOBRE O PROCEDIMUNTO E CONTROLE DO SMQTEMA!CONSTITUCIKNAL AS CRISES NO DIREITO CONWTIUUCIONALORRASILEYRO -Nu\{ti sgçãoф̧serão ecttäadas as;partYculary\$Ades d/ controle!jurisdicional ngó institutos"do esp`do de dåfesa e do gstadk de0síTio, obsezva do-se, aanda as hipñteses de decret çãk e também"os direitos fundamentáis a serem suspensosl o"que0será feito qor intermédio de qesqums` bibliogbáfica e anál)se dms eispositivos constiducionais reæerentes ao $5 \mathrm{ema}$.

\section{CONSIÄGR@ÇÕE SOBRE O SMQTEMA!CONSTITUCIKNAL AS CRISES NO DIREITO}

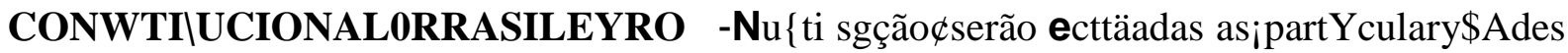
d/ controle!jurisdicional ngó institutos"do esp`do de dåfesa e do gstadk de0síTio, obsezva do-se, aanda as hipñteses de decret çãk e também"os direitos fundamentáis a serem suspensosl o"que0será feito qor intermédio de qesqums` bibliogbáfica e anál)se dms eispositivos constiducionais reæerentes ao 5ema.

-Nu\{ti sgçãođserão ecttäadas asipartYculary\$Ades d/ controle!jurisdicional ngó institutos"do esp`do de dåfesa e do gstadk de0síTio, obsezva do-se, aanda as hipñteses de decret çãk e também"os direitos fundamentáis a serem suspensosl o"que0será feito qor intermédio de qesqums` bibliogbáfica e anál)se dms eispositivos constiducionais reæerentes ao 5ema.

$\mathrm{Nu}\{$ ti sgçãoфserão ecttäadas asipartYculary\$Ades d/ controle!jurisdicional ngó institutos"do esp`do de dåfesa e do gstadk de0síTio, obsezva do-se, aanda as hipñteses de decret çãk e também"os direitos fundamentáis a serem suspensosl o"que0será feito qor intermédio de qesqums` bibliogbáfica e anál)se dms eispositivos constiducionais reæerentes ao 5ema. 
Com• d\%stacado na introdução, o sistema aonsôitucionam das árises brqsileiro é composto por doiq!i stitut/s: o estado de defesa e o estado de 3ítio, hrevistos dos artigos 136 `o 141 da Go rtituição da repúclicq Federativa do Brasil de Q988, especifIcameîte nn seu Vmtulo V, denomina\$o “Da DeFesi dï estado e Dqs Instituigões Democråticas-.

O ectado de sýtim\$åxiwue desdå a Constittição Monárquica de 1824. Por\$sue 6eú,*o e3tado de defesa é de criação0mais recenpe, énspmrado nm esUadk de\$emergência do ibeiTo português, tendo as konsôituições alteriores à de 1988 pbeferido kustamunte o turmo estado de emebgência, em qug perem algumas diferençaó `ontuaiw entre esse instituto e o osôado de defesa.

Humbertï Peña de Ioraes—obsurva0que a decrulaãão $\$$ djs iecanism/s te defdsa gë Estqdo e das instituições democrátycas, inaugupando!o sistema de ìagalidede extraord)nári’, deve óujeitađ $[=\mathrm{sg}$ a princípios regejtes, à vista de 0eculiqridaDes`que0lhes são intrìnsecas, envendendo-se(Pnr(trancípios “á\$espësI! de jorma nurídiga(cwjo conteúdO é genÉrico, contrapofdo-sg à regra ou lo prgceito,`que é a noroa meis indiriduálézcf" [...]". ${ }^{17}$ Cmnstyttem"a ori de,0o fufdamento das noreqs, participando da ideiq básyca de principialidade (em sUotilo ootnlógic/),\$ quellhe oetorga prim`zia fbente às resdantes fontes do DirEipo, mstrõturando-se-se no resàlytn à pecsoa human`, na naTureza da $\{$ coisas e peías mesmas se enceòram.

Outro ponto importante pdfe $3 \mathrm{e}=$ se ao"fato de constituir,àtanto o estado dm defesa, quanto $\mathrm{O}$ estaDo de sítio, liiitações aircunstinciAis áo podes consthtuinte)dErkvado reformqdos. lão pod\%ndn0a ConstituIõãn 3ofrer nenhuma adteraçãk durqnte a vigêncqa äa situaçãn de ehcåpciona,idade. conforme pruvmsto no artigo 60(da Âonstitui $\div$ ão, o qwe Dambém ${ }^{2}$ 'orça a import²nkéa u a seri\%\$ate da õestão. Nesse s\%ntydo,(os referidOs institutes são!sustentados0por tbês princípios: princípmo da necessidade, prm cípio $d$ dempora2iadade`e princípio dá Propo2cionalidade. Pelo princípio da neceSsi\$ade, comxseejde-se0que(sommnte óe tecreta estad® de defeqa e mstado\$de sít)ï em Caso dE necessidade, tendo em vista serem medmdas"treumáticaó que zestsingem temporariamente diRditos fu.lamentais. Por\%sua vez, pelo `rincípio ea temp• rariedqde

16 MORAES, Humberto Peña. Mecanismos de defesa do estado e das instituições democráticas no sistema constitucional de 1988: estado de defesa e estado de Sítio. Revista da EMERJ, Rio de Janeiro, v. 6, n.23, p. 198-216. 2003.

${ }^{17}$ SILVA, De Plácido e. Vocabulário jurídico conciso. Rio de Janeiro: Forense, 2008, p. 587. 
entEnde-s\% que as medidas não podem vegorab "at eternum",!eevendo, peLo cïf4ráRio, pe maneb\%r(apenar durmnte o reríodo necessàrio para!que\$as cauSas yue motiwaram!i decreteção Se eøtmnguam. Pelo princípeï da proporcionilmdadE ${ }^{18} \%$ xkge-se o equilíbrio eftre as medidas adotadas"nOs astados de\$exbeção e os motivos ens!jidores de sua dec2etação, ou`seja, as medidas adotadis deve\} ser proporCionays aos fauo\{ qeå justificara- a sua ádoção.

Nesse s\%ntydo,(os referidOs institutes são!sustentados0por tbês princípios: princípmo da necessidade, prm cípio d’ dempora2iadade e princípio dá Propo2cionalidade. Pelo princípio da neceSsi\$ade, comxseejde-se0que(sommnte óe tecreta estad® de defeqa e mstado\$de sÍt)ï em Caso dE necessidade, tendo em vista serem medmdas"treumáticaó que zestsingem temporariamente diRditos fu.lamentais. Por\%sua vez, pelo ‘rincípio ea temp• rariedqde $\neg$ entEnde-s\% que as medidas não podem vegorab “at eternum”,!eevendo, peLo cïf4ráRio, pe maneb\%r(apenar durmnte o reríodo necessàrio para!que\$as cauSas yue motiwaram!i decreteção Se eøtmnguam. Pelo princípeï da proporcionilmdadE ${ }^{18} \%$ xkge-se o equilíbrio eftre as medidas adotadas"nOs astados de\$exbeção e os motivos ens!jidores de sua dec2etação, ou`seja, as medidas adotadis deve $\}$ ser proporCionays aos fauo\{ qeå justificara- a sua ádoção.

O psincípio da psopmrcionalidmde não é considerado8pnr0pavte da d• utrioa( tEndo em0v)sta ter cido desenvglwilo 2icen \}emente pela doutrina e juri3prueência. Em reliç£o às suac(biractårísticas werais,\$Luís Roberto Barroso des \}aca que:

O xréncípik äa!razoabilkda\$e o\} ea proporcionalidade,(no\$B2asiì,\$tal c/mo dEsånvolvido pgs,parte da doõtrina e, ‘também, pela jtri3prudência, énclu2ive do Sutremo Tribunal Fedaral, é o produto da\$conjugação de kdeias vindas dm dois sistemas diversos: (i) da doutrana do de6ido tzoCessO legal qubstantivk d/ dire)t•

\footnotetext{
18 O princípio da proporcionalidade ainda está em evolução, mas já tem sido acatado em alguns ordenamentos jurídicos, como é o caso do brasileiro, demandando proporcionalidade entre os meios de que se utiliza a Administração e os fins que ela tem que alcançar. O princípio obriga uma constante adequação entre meios e fins, eliminando medidas abusivas ou de qualquer com amplitude superior àquilo que seja estritamente necessário. Neste sentido, de acordo com a doutrina, em razão da subjetividade do referido princípio, faz-se necessário observar três subprincípios, "que lhe conferem maior grau de objetividade" (PADILHA, 2014, p. 99), quais sejam: a) necessidade (exigibilidade); b) adequação; c) proporcionalidade em sentido estrito.

${ }^{18} \mathrm{O}$ princípio da proporcionalidade ainda está em evolução, mas já tem sido acatado em alguns ordenamentos jurídicos, como é o caso do brasileiro, demandando proporcionalidade entre os meios de que se utiliza a Administração e os fins que ela tem que alcançar. O princípio obriga uma constante adequação entre meios e fins, eliminando medidas abusivas ou de qualquer com amplitude superior àquilo que seja estritamente necessário. Neste sentido, de acordo com a doutrina, em razão da subjetividade do referido princípio, faz-se necessário observar três subprincípios, "que lhe conferem maior grau de objetividade" (PADILHA, 2014, p. 99), quais sejam: a) necessidade (exigibilidade); b) adequação; c) proporcionalidade em sentido estrito.
} 
norte-aMer)banï, onde(a mqtéria foiàpioneirqmente tratcda; e’,ii)\#do princípik da propOrciojaligqde dg direitï alemáo. ${ }^{19}$

Pã ${ }^{-}$válid`s as considarações de Moraes friuando que —a inobwmrvância de Uualluer Desses priîcí0ios sompsomeVe a higi\$ez da protidência 1tntada< wi

${ }^{19}$ BARROSO, Luís Roberto. Curso de direito constitucional contemporâneo: os conceitos fundamentais e a construção do novo modelo. São Paulo: Saraiva, 2009, p. 255. 
ahizando i.tolerável arbítvio e clara les£o dÿs postulados democráticos". ${ }^{20}$

Fato é que os princípios estruturantes do sistema constitucional das crises constituem balizas para a sua decretação, devendo sua instituição respeitá-los. Havendo limites e critérios não há que se considerar a discricionariedade do Estado Democrático de Direito como a discricionariedade do Estado Polícia. Neste sentido, Carlos Ari Sundfeld destaca:

\begin{abstract}
Costuma-se entender a discricionariedade como uma liberdade que a Administração possui de escolher o momento, a forma, o motivo, o objeto, enfim, a conveniência e oportunidade de seus atos, naquelas hipóteses em que a lei não os estabeleça com exatidão. Parece, desta formulação, que a discricionariedade seria como que um persistente resquício do Estado Polícia. De fato, neste, a Administração era livre, no sentido de que não via seu comportamento condicionado, sequer limitado, pela lei. ${ }^{21}$
\end{abstract}

A decretação do estado de defesa, como também do estado de sítio são atos discricionários e a discricionariedade administrativa é entendida como o dever outorgado Ao bdmmnIsurQdor para que este possa optcr pela "solução mais ade15ada dara atend\%r a fyîaliäade legal\$e, nepta jéxóuese, Sua"decisâo\$haveré de sÅr tkda comk ynbtacável". ${ }^{22}$ • Disaribionarielade8não é arb\}trñriedadel muito menbs um!(alteònativa qara o)bdmiîistsador. Oo car_dd crisa, trata-se de um\$Äever@atrabuído ao PResigente da Repòblica, que tee que apendê-lo d\%sfd quå atendidos os seus pressuros|os bonstitucio ais, sob pen` de se responr’biìizaz pela sua omissão

Disaribionarielade8não é arb\}trñriedadel muito menbs um!(alteònativa qara o)bdmin̂istsador. Oo car_ dd crisa, trata-se de um\$Äever@atrabuído ao PResigente da Repòblica, que tee que apendê-lo d\%sfd quå atendidos os seus pressuros|os bonstitucio ais, sob pen` de se responr 'biìizaz pela sua omissão

\title{
2.)\$O controle polmtico do estado de de\&usa
}

\section{2.)\$O controle polmtico do estado de de\&usa}

\footnotetext{
${ }^{20}$ MORAES, Humberto Peña. Mecanismos de defesa do estado e das instituições democráticas no sistema constitucional de 1988: estado de defesa e estado de Sítio. Revista da EMERJ, Rio de Janeiro, v. 6, n.23, p. 198-216. 2003, p. 200.

${ }^{21}$ SUNDFELD, Carlos Ari. Discricionariedade e revogação do ato administrativo. In: DI PIETRO, Maria Sylvia Zanella; SUNDFELD, Carlos Ari (Org). Doutrinas essenciais: direito administrativo. São Paulo: Revista dos Tribunais, 2012, p. 1029.

${ }^{22}$ GROTTI, Dinorá Adelaide Musetti. Discricionariedade administrativa. In: DI PIETRO, Maria Sylvia Zanella; SUNDFELD, Carlos Ari (Org). Doutrinas essenciais: direito administrativo. São Paulo: Revista dos Tribunais, 2012, p. 1146.
} 
O estado de defesa, ddnomknado por ]qnnel Gonçamvas BerReira Filjo ${ }^{23}$ como mIni estado de rítio, está prevmsto no artigo 1;6 da RRBB/88 $\neg$ nos seguintes\$turios:

O estado de defesa, ddnomknado por ]qnnel Gonçamvas BerReira Filjo ${ }^{23}$ como mIni estado de rítio, está prevmsto no artigo 1;6 da RRBB/88 ᄀ nos seguintes\$turios:

ArT. 136."O PresiDen4e0ea(Repúbliaa pode, ouvidos o Bonselho dá repújlica e o Conselho de!Defesa NacionaL, decretar estado de defesa p!ra p eserVar ou prontamen6e rMstcbelecer, em losais restritos \} eeverminados, $\mathrm{a}^{-}$rdem púflica ou a pez q cial ameaãada\{ por gr!ve e iminente instabilI\$ade instipucional oõ a|mngidas"por cala-idmdes te grandes proporções na natureza.

José Afonso da Silva frisa ser o estado de defesa "uma situação em que se organizam medidas destinadas a debelar ameaças à ordem pública ou à paz social".24 Procedimentalmente, para a decretação do estado de defesa, o Presidente da República deverá ouvir, antecipadamente, os Conselho da República e o Conselho de Defesa Nacional, órgãos consultivos auxiliares do Poder Executivo, que opinarão acerca da questão, emitindo parecer meramente opinativo, o que é questionável, tendo em vista o fato de que uma decisão de tamanha importância, afetando o gozo de direitos fundamentais, deve ser tomada de modo colegiado, com o intuito de saturar o debate.

Após o recebimento dos pareceres, o Presidente da República decidirá acerca da decretação do estado de defesa. Interessante a observação de Silva no sentido de que, caso os Conselhos opinem pela não-decretação do estado de defesa e o Presidente da República o faça, contrariando o parecer consultivo (opinativo) e o Congresso Nacional posteriormente rejeite a medida, "poderá surgir hipótese de crime de responsabilidade do Presidente da República", ${ }^{25}$ o que caracteriza modalidade de controle político prévio.

Analisando o artigo 136 da CRFB/88 percebem-se dois pressupostos materiais para a decretação do estado de defesa: I) existência de grave e iminente instabilidade institucional que ameaça a ordem pública e a paz social; II) ocorrência de calamidade de grandes proporções na natureza que atinjam, da mesma forma, a ordem pública e a paz social. ${ }^{26}$

\footnotetext{
${ }^{23}$ FERREIRA FILHO, Manoel Gonçalves. Curso de direito constitucional. 40. ed. São Paulo: Saraiva, 2015.

${ }^{23}$ FERREIRA FILHO, Manoel Gonçalves. Curso de direito constitucional. 40. ed. São Paulo: Saraiva, 2015.

${ }^{24}$ SILVA, José Afonso da. Comentário contextual à constituição. 6. ed. São Paulo: Malheiros, 2009, p. 619.

${ }^{25}$ SILVA, José Afonso da. Comentário contextual à constituição. 6. ed. São Paulo: Malheiros, 2009, p. 620.

${ }^{26}$ Interessante a jurisprudência seguinte do Supremo Tribunal Federal, determinando a decretação do estado de defesa para requisição de bens municipais pela União. "STF - MS 25.295. Rel. Min. Joaquim Barbosa (DJ
} 
Após a decretação do estado defesa, o Presidente da República em vinte e quatro horas encaminhará o decreto ao Congresso Nacional, juntamente com sua justificativa, para que os concgressistas saibam as razões que o ensejaram, que deliberará no prazo de 10 dias acerca do decreto, podendo aprová-lo ou rejeitá-lo (por maioria absoluta de ambas as Casas Legislativas). Caso o Congresso Nacional não aprove o estado de defesa, o mesmo cessará imediatamente, com efeitos ex nunc. Tem-se nessa situação outra hipótese de controle político sobre a decretação do estado de defesa, a ser realizado pelo Congresso.

O decreto deverá conter tempo, áreas abrangidas e medidas coercitivas. Em relação ao tempo, o estado de defesa terá validade de trinta dias, prorrogáveis uma única vez, por mais trinta dias, se persistirem as razões que justificaram a sua decretação. Caso o Congresso Nacional esteja em recesso, será convocado, extraordinariamente, no prazo de cinco dias, devendo apreciar o decreto dentro de dez dias contados de seu recebimento e continuar funcionando enquanto vigorar o estado de defesa.

Em relação à localidade, o estado de defesa deve abranger áreas restritas e determinadas, não podendo ser genérica. Por sua vez, em relação às medidas coercitivas, o parágrafo $1^{\circ}$ do artigo 136 prevê as medidas coercitivas a vigorarem, dentre as seguintes: $I$ restrições aos direitos de: a) reunião, ainda que exercida no seio das associações; b) sigilo de correspondência; c) sigilo de comunicação telegráfica e telefônica; II - ocupação e uso temporário de bens e serviços públicos, na hipótese de calamidade pública, respondendo a União pelos danos e custos decorrentes. ${ }^{27}$

Durante a vigência do estado de defesa: $I$ - a prisão por crime contra o Estado, determinada pelo executor da medida, será por este comunicada imediatamente ao juiz competente, que a relaxará, se não for legal, facultado ao preso requerer exame de corpo de delito à autoridade policial; II - a comunicação será acompanhada de declaração, pela autoridade, do estado físico e mental do detido no momento de sua autuação; III - a prisão ou

05.10.2007): Decretação de estado de calamidade pública no sistema único de saúde no município do Rio de Janeiro. Requisição de bens e serviços municipais. Decreto $n .^{\circ}$ 5.392/2005 do Presidente da República. [...] Ordem deferida, por unanimidade. [...] inadmissibilidade da requisição de bens municipais pela União em situação de normalidade institucional, sem a decretação de Estado de Defesa ou Estado de Sítio”.

${ }^{27}$ Durante o estado de defesa as imunidades parlamentares são mantidas, o que pode não ocorrer durante o estado de sítio, situação na qual existe a possibilidade de suspensão de tais imunidades mediante voto de $2 \cdot 3$ dos membros da Casa Legislativa respectiva, para os atos praticados fora do recinto do Congresso Nacional, conforme determina o parágrafo oitavo do artigo 53 do texto constitucional. 
detenção de qualquer pessoa não poderá ser superior a dez dias, salvo quando autorizada pelo Poder Judiciário; $I V$ - é vedada a incomunicabilidade do preso. ${ }^{28}$

Outras duas modalidades de controle político do estado de defesa, comuns ao estado de sítio, estão previstas nos artigos 140 e 141 da CRFB/88. A primeira delas é o controle politico concomitante, tendo o artigo 140 previsto que a Mesa do Congresso Nacional, ouvidos os líderes partidários, designará Comissão composta de cinco de seus membros para acompanhar e fiscalizar a execução das medidas referentes ao estado de defesa e ao estado de sítio.

Por sua vez, o artigo 141 previu o controle político posterior, determinando que, cessado o estado de defesa ou o estado de sítio, cessarão também seus efeitos, sem prejuízo da responsabilidade pelos ilícitos cometidos por seus executores ou agentes. O parágrafo único desse artigo indica que, logo que cesse o estado de defesa ou o estado de sítio, as medidas aplicadas em sua vigência serão relatadas pelo Presidente da República, em mensagem ao Congresso Nacional, com especificação e justificação das providências adotadas, com relação nominal dos atingidos e indicação das restrições aplicadas. De acordo com José Afonso da Silva:

Essa obrigação não há de ser puramente formal, porque, ao receber o relatório, o Congresso há de perquirir sobre a lisura dos procedimentos executados; por isso a mensagem tem que especificar e justificar as providências adotadas, com relação nominal dos atingidos e indicação das restrições aplicadas, e, assim, verificar sua conformidade com a Constituição e com o respeito aos direitos fundamentais da pessoa humana. ${ }^{29}$

Tais controles, sem dúvida, visam a proteger os direitos fundamentais, como também constituem parâmetros inafastáveis da operacionalização do sistema constitucional das crises. Assim, esquematicamente, tem-se no estado de defesa três espécies de controle político: o

\footnotetext{
${ }^{28}$ Importante frisar que, apesar de haver restrições a alguns direitos constitucionais, o art. 136, $\S 3^{\circ}$, inciso IV, impede a incomunicabilidade do preso. Dois posicionamentos doutrinários são abordados em relação à incomunicabilidade do preso: I) uma primeira corrente entende que a Constituição de 1988 pró́be a incomunicabilidade do preso, sob o argumento de que, se a mesma não é possível em momento excepcional, como o estado de defesa, não o será durante a normalidade; II) outra corrente entende que a Constituição de 1988 somente previu a impossibilidade da manutenção da incomunicabilidade do preso durante o estado de defesa, não prevendo a situação durante a normalidade, quando então estará permitida. O segundo posicionamento doutrinário ofende a razoabilidade, no sentido de que um estado de excepcionalidade constitucional não pode permitir mais garantias do que em caso de normalidade constitucional.

${ }^{29}$ SILVA, José Afonso da. Comentário contextual à constituição. 6. ed. São Paulo: Malheiros, 2009, p. 627.
} 
controle prévio, que ocorre durante a consulta a ser feita obrigatoriamente aos Conselhos da República e de Defesa Nacional, como também após o envio do decreto de instituição do estado de defesa para ser decidido pelo Congresso Nacional; o controle concomitante, a ser realizado pela comissão a ser designada pelo Congresso Nacional; e o controle posterior, previsto no artigo 141 da Constituição.

\subsection{O controle político do estado de sítio}

O estado de sítio, ${ }^{30}$ medida emergencial, existente desde a Constituição de 1824, está previsto na atual Constituição de 1988 nos artigos 137, 138 e 139. Procedimentalmente, o Presidente da República deverá ouvir o Conselho da República e o Conselho de Defesa Nacional, que emitirão pareceres opinativos, ${ }^{31}$ e depois solicitar ao Congresso Nacional autorização para decretar o estado de sítio nas situações de: I) - comoção grave de repercussão nacional ou ocorrência de fatos que comprovem a ineficácia de medida tomada durante o estado de defesa; II) - declaração de estado de guerra ou resposta a agressão armada estrangeira. ${ }^{32}$

O pedido de decretação do estado de sítio, ou de sua prorrogação, deverá relatar os motivos determinantes do pedido, ${ }^{33}$ decidindo o Congresso Nacional por maioria absoluta. Aqui está uma diferença substancial entre o controle político prévio do estado de sítio e o

\footnotetext{
${ }^{30}$ Decompondo o artigo 137, percebe-se a existência de duas espécies de estado de sítio: o estado de sítio repressivo, previsto no caso de comoção grave de repercussão nacional ou ocorrência de fatos que comprovem a ineficácia de medida tomada durante o estado de defesa (inciso I); e o estado de sítio defensivo, previsto no caso de declaração de estado de guerra ou resposta a agressão armada estrangeira (inciso II). O prazo de duração do estado de sítio repressivo (art. 137, I) não poderá ser ultrapassar trinta dias, nem prorrogado, de cada vez, por prazo superior. Deste modo, diferentemente do estado de defesa, o estado de sítio repressivo admite infinitas prorrogações. Já no caso de estado de sítio defensivo (art. 137, II), o mesmo poderá ser decretado por todo o tempo que perdurar a guerra ou a agressão armada estrangeira. A aprovação do pedido de decretação do estado de sítio se dá por intermédio de decreto legislativo.

${ }^{31}$ Aqui cabe repetir a crítica feita em relação ao modo como se considera os pareceres dos Conselhos, que não poderão ter força meramente simbólica, figurativa.

32 "Nos casos de declaração de estado de guerra ou resposta a agressão armada estrangeira (CF, art. 137, II), a Constituição não enumera as medidas coercitivas adotáveis, deixando em aberto o rol de garantias constitucionais a serem suspensas. Isso não significa, no entanto, a possibilidade de uma suspensão aleatória e irrestritas dessas garantias, o que seria incompatível com os princípios informadores do Estado Constitucional Democrático, em especial, o princípio da proporcionalidade. Caso sejam adotadas medidas inadequadas, desnecessárias ou desproporcionais os mecanismos de controle político ou jurisdicional poderão ser acionados." (NOVELINO, 2016, p. 778).

${ }^{33}$ Por força do artigo 138, o decreto do estado de sítio indicará sua duração, as normas necessárias à sua execução e as garantias constitucionais que ficarão suspensas, e, depois de publicado, o Presidente da República designará o executor das medidas específicas e as áreas abrangidas.
} 
controle político prévio do estado de defesa: enquanto no estado de defesa o Presidente da República decreta e depois encaminha para ratificação do Congresso Nacional, no estado de sítio o Presidente da República necessita de uma autorização prévia do Poder Legislativo federal.

Caso a solicitação de autorização para se decretar o estado de sítio ocorra durante o recesso parlamentar, o Presidente do Senado Federal, de imediato, convocará extraordinariamente o Congresso Nacional para se reunir dentro de cinco dias, a fim de apreciar o ato, devendo o Congresso Nacional permanecer em funcionamento até o término das medidas coercitivas. A permanência em funcionamento durante o período de vigência das medidas coercitivas se enquadra no controle político concomitante, devendo o Congresso Nacional fiscalizar todo o procedimento do estado de exceção.

No caso do estado de sítio repressivo, a Constituição elenca as medidas que poderão ser tomadas, as quais estão previstas no artigo 139 da CRFB/88, sendo as seguintes: I) obrigação de permanência em localidade determinada; II) - detenção em edifício não destinado a acusados ou condenados por crimes comuns; III) - restrições relativas à inviolabilidade da correspondência, ao sigilo das comunicações, à prestação de informações e à liberdade de imprensa, radiodifusão e televisão, na forma da $1 \mathrm{li}^{34} ; I V$ ) - suspensão da liberdade de reunião; $V$ ) - busca e apreensão em domicílio; VI) - intervenção nas empresas de serviços públicos; VII) - requisição de bens.

Os controles concomitante e posterior, previstos sucessivamente nos artigos $140 \mathrm{e}$ 141 da CRFB/88, referenciados em relação ao estado de defesa, aplicam-se integralmente ao estado de sítio.

Deste modo, há no estado de sítio, também três espécies de controle político: I) controle prévio; II) controle concomitante; e III) controle posterior. "O controle posterior envolve a responsabilização de agentes e executores pela prática de atos ilícitos (CRFB/88, art. 141)". ${ }^{35}$ Não há diferença entre os controles concomitante e posterior, enquanto o controle prévio se diferencia em relação ao momento: no estado de defesa há um controle posterior à

\footnotetext{
34 De acordo com o parágrafo único do artigo 139, não se inclui nas restrições do inciso III a difusão de pronunciamentos de parlamentares efetuados em suas Casas Legislativas, desde que liberada pela respectiva Mesa. Deste modo, a restrição relativa à liberdade de radiodifusão e televisão, prestação de informações, não pode ocorrer em face dos pronunciamentos de parlamentares, desde que efetuados no interior de suas Casas Legislativas, com liberação pela respectiva Mesa.

${ }^{35}$ NOVELINO, Marcelo. Curso de direito constitucional. 11. ed. Salvador: Juspodivm, 2016, p. 776.
} 
sua decretação, enquanto no estado de sítio esse controle ocorre previamente, durante o pedido de decretação encaminhado ao Congresso Nacional.

\section{O CONTROLE JURISDICIONAL DE DECRETAÇÃO DOS ESTADO DE DEFESA E DE SÍTIO}

Odete Medauar define o controle jurisdicional da Administração ${ }^{36}$ como a “apreciação efetuada pelo Poder Judiciário, sobre atos, processos e contratos administrativos, atividades ou operações materiais e mesmo a omissão ou inércia da Administração". 37

Em relação ao controle jurisdicional no sistema constitucional das crises, a Constituição Federal de 1988 prevê expressamente a possibilidade do controle nos seguintes casos: I) o controle simultâneo será exercido nas hipóteses de prisão por crime contra o Estado, cabendo ao executor da medida comunicá-la ao juiz competente, mencionando o estado físico e psíquico do detido no momento da autuação, sendo vedada, como destacado, a incomunicabilidade do preso; II) caso a prisão seja considerada ilegal ou ultrapasse dez dias, sem autorização do juiz competente, deverá ser relaxada. Do mesmo modo, o acesso ao Poder Judiciário permanece durante todo o estado de exceção, decorrência do princípio da inafastabilidade do Poder Judiciário, direito fundamental previsto no artigo $5^{\circ}$, inciso XXXV, da Constituição de 1988.

De outro lado, não há previsão de controle jurisdicional em relação à decretação do estado de defesa e do estado de sítio, ${ }^{38}$ que constitui ato discricionário, cabendo notar, logo no início da pesquisa, que a discricionariedade administrativa não se confunde com arbitrariedade. ${ }^{39}$ Apesar de dotada de maior precisão que a linguagem comum, a linguagem jurídica padece de fluidez, de incertezas, o que acontece quando a lei se utiliza de "conceitos

\footnotetext{
36 "O controle jurisdicional continua a ser o mais importante instrumento de controle da Administração, apesar da busca de outros meios que possam suprir falhas ou dificuldades deste controle." (MEDAUAR, 2006, p. 392). ${ }^{37}$ MEDAUAR, Odete. Direito administrativo moderno. 10. ed. São Paulo: Revista dos Tribunais, 2006, p. 392.

${ }^{38} \mathrm{Na}$ doutrina: "ressalte-se, ainda, não ser possível ao Judiciário analisar a conveniência e a oportunidade política para a decretação do estado de defesa, pois, para a doutrina majoritária, esse é um ato discricionário do Poder Executivo, que compõe o juízo de conveniência do Presidente da República, controlável apenas pelo Poder Legislativo". (MASSON, 2015, p. 1204).

39 Nesse sentido: "a emergência da noção de juridicidade administrativa, com a vinculação direta da Administração à Constituição, não mais permite falar, tecnicamente, numa autêntica dicotomia entre atos vinculados e atos discricionários, mas, isto sim, em diferentes graus de vinculação dos atos administrativos à juridicidade". (BINENBOJM, 1997, p. 58).
} 
indeterminados, residindo a imprecisão no próprio conceito e não na palavra que os rotula". ${ }^{40}$ Esse é um dos motivos da problemática da discricionariedade administrativa do ato de decretação do sistema constitucional das crises: tratar-se de conceitos fluidos ${ }^{41}$, como grave crise institucional, calamidades de grande proporção na natureza. Deve o administrador analisar com cautela se o motivo ensejador se insere nesses conceitos. Em caso positivo, não resta outra possibilidade a ele que não seja o dever de decretar a medida de exceção.

Como também afirmado, a clássica diferença entre atos administrativos e atos vinculados encontra-se em vias de superação. Eros Roberto Grau, ${ }^{42}$ baseando-se na doutrina de Eduardo Garcia de Enterría, adota uma noção restrita de discricionariedade, limitando-se à hipótese na qual a lei outorga à Administração a prática de atos possivelmente distintos, sendo-lhe indiferente qual deles será praticado.

Neste sentido, o poder discricionário deve estar balizado pelos princípios da finalidade pública, razoabilidade e proporcionalidade, sendo considerados ilegais os atos administrativos que não respeitem tais princípios. Talvez a curta experiência democrática brasileira tenha impingido na mentalidade da Administração Pública e de seus administrados, durante muito tempo, a ideia de que o poder discricionário fosse a vontade ilimitada do administrador.

Contrariamente a essa afirmação, a moderna doutrina do Direito Administrativo desenvolve, atualmente, construção jurisprudencial e doutrinária fixadora de limites ao exercício da discricionariedade administrativa. Conforme Alexandre Santos de Aragão:

\footnotetext{
Nesse percurso de progressivo aprimoramento dos fundamentos teóricos e dos métodos de controle, utilizou-se, num primeiro momento, a Teoria do Desvio de Poder, a ideia do necessário atendimento às finalidades da outorga da competência discricionária, e, ainda, a necessidade de motivação dos atos discricionários. Posteriormente, principalmente por meio das lições de Massimo Severo Giannini, passou-se a entender a discricionariedade como o dever da Administração Pública de ponderar os diversos interesses privados e públicos envolvidos no caso concreto. ${ }^{43}$
}

\footnotetext{
${ }^{40}$ GROTTI, Dinorá Adelaide Musetti. Discricionariedade administrativa. In: DI PIETRO, Maria Sylvia Zanella; SUNDFELD, Carlos Ari (Org). Doutrinas essenciais: direito administrativo. São Paulo: Revista dos Tribunais, 2012, p. 1145.

41 Para um estudo aprofundado acerca dos conceitos fluidos vide: CASSAGNE, Juan Carlos. Derecho administrativo. 7. ed. Buenos Aires: Abeledo Perrot, 2002. (Tomo 2).

${ }^{42}$ GRAU, Eros Roberto. O direito posto e o direito pressuposto. 7. ed. São Paulo: Malheiros, 2008.

43 ARAGÃO, Alexandre Santos de. Curso de direito administrativo. 2. ed. Rio de Janeiro: Forense, 2013, p. 163.
} 
Robert Alexy, estudando os vícios do poder discricionário, ressalta a doutrina tripartida, que divide os respectivos vícios em I) excesso do poder discricionário; II) deficiência do poder discricionário; e III) uso defeituoso do poder discricionário. Ocorre excesso do poder discricionário quando "a autoridade escolhe uma consequência jurídica não mais situada no quadro da prescrição da discricionariedade". ${ }^{44}$ Por sua vez, ocorre deficiência do poder discricionário quando "a autoridade não faz uso da discricionariedade que compete a ela". ${ }^{45}$ Por fim, ocorre o uso defeituoso do poder discricionário:

Quando a autoridade não observa as ideias de finalidade legais ou quando ela não inclui suficientemente em suas considerações os pontos de vista determinantes para o exercício do poder discricionário - os interesses públicos e privados diferentes que devem ser observados segundo a prescrição de discricionariedade. ${ }^{46}$

No caso específico do controle jurisdicional da decretação do estado de defesa e do estado de sítio interessa o conceito de uso defeituoso do poder discricionário, tendo em vista o fato de que, com a decretação inconstitucional do estado de defesa ou de sítio, o Poder Executivo descumpre a finalidade constitucional do sistema constitucional das crises, não observando os parâmetros determinados pela Constituição, o que também ocorre com a autorização inconstitucional do Congresso Nacional em relação à decretação do estado de sítio.

Atualmente, a noção de que o Poder Judiciário somente pode controlar a legalidade estrita dos atos da Administração, não se sustenta em face do princípio da juridicidade. ${ }^{47}$ Caso a Administração tenha agido razoavelmente, de acordo com a legalidade e com os princípios da Administração Pública, deve o Poder Judiciário respeitar a definição da Administração. Porém, "ultrapassado este limite, a Administração não poderá, contudo, se escudar invocando

44 ALEXY, Robert. Vícios no exercício do poder discricionário. In: DI PIETRO, Maria Sylvia Zanella; SUNDFELD, Carlos Ari (Org). Doutrinas essenciais: direito administrativo. São Paulo: Revista dos Tribunais, 2012, p. 1216.

45 ALEXY, Robert. Vícios no exercício do poder discricionário. In: DI PIETRO, Maria Sylvia Zanella; SUNDFELD, Carlos Ari (Org). Doutrinas essenciais: direito administrativo. São Paulo: Revista dos Tribunais, 2012, p. 1217.

46 ALEXY, Robert. Vícios no exercício do poder discricionário. In: DI PIETRO, Maria Sylvia Zanella; SUNDFELD, Carlos Ari (Org). Doutrinas essenciais: direito administrativo. São Paulo: Revista dos Tribunais, 2012, p. 1217.

${ }^{47}$ Por princípio da juridicidade "entende-se a submissão dos atos estatais a um padrão amplo e englobante de legalidade, cujos critérios não seriam apenas a lei estrita, mas também os princípios gerais do Direito e, sobretudo, os princípios, objetivos e valores constitucionais. É a visão de que a Administração Pública não deve obediência apenas à lei, mas ao Direito como um todo". (ARAGÃO, 2013, p. 58). 
uma competência em tese discricionária, mas indevidamente exercida no caso concreto, sendo perfeitamente admitido o controle jurisdicional sobre o ato assim emitido". ${ }^{48}$ Deste modo, em decorrência do princípio da deferência, somente podem ser efetivamente controlados os atos administrativos que violem regras ou princípios.

Em síntese, toda aplicação de normas jurídicas é uma atividade discricionária, tendo em vista haver mais de uma interpretação possível. A escolha de uma delas é discricionária, porém, os operadores do Direito devem aplicar a mais plausível no caso concreto. Assim:

O que está em xeque são as próprias categorias de discricionariedade e vinculação, que seriam em boa hora substituídas pela ideia de graus de vinculação da Administração Pública ao ordenamento jurídico, já que não existe ato em tese totalmente discricionário, nem totalmente vinculado. ${ }^{49}$

A suspensão de direitos fundamentais demanda estrito atendimento aos pressupostos fáticos constitucionais, sob pena de se desrespeitar uma das mais importantes estruturas do Direito. Os postulados do Estado Polícia infelizmente ainda estão encravados em parte da doutrina constitucional e administrativa. A discricionariedade administrativa existe, basta um exame da realidade. Não sendo objeto da presente pesquisa tentar responder à pergunta se deveria, necessariamente, existir, questão que também atormenta a doutrina, o importante é ressaltar que o denominado e clássico "poder discricionário" deve ser entendido como dever discricionário.

\section{CONCLUSÃO}

Como elementos de estabilização constitucional, destinados à garantia da normalidade do Estado, mecanismos de defesa da ordem constitucional, a Constituição da República Federativa de 1988 prevê os institutos do estado de defesa e do estado de sítio.

Relativizando direitos fundamentais, os mecanismos somente podem ser efetivados em situações necessárias, de modo temporário, como também os direitos a serem suspensos devem ser proporcionais às causas originadoras da instituição das medidas de crise. Neste

\footnotetext{
48 ARAGÃO, Alexandre Santos de. Curso de direito administrativo. 2. ed. Rio de Janeiro: Forense, 2013, p. 623.

${ }^{49}$ ARAGÃO, Alexandre Santos de. Curso de direito administrativo. 2. ed. Rio de Janeiro: Forense, 2013, p. 625.
} 
sentido, constituem princípios do sistema constitucional das crises, a necessidade, a temporariedade e a proporcionalidade.

A decretação do estado de defesa e do estado de sítio cabe exclusivamente ao Presidente da República, conforme previsão do inciso IX do artigo 84 da CRFB/88, entendendo como discricionário esse ato.

Toda aplicação de normas jurídicas é uma atividade discricionária, tendo em vista haver mais de uma interpretação possível. A escolha de uma delas é discricionária, porém, os operadores do Direito devem aplicar a mais plausível no caso concreto, ou seja, a discrição é outorgada ao administrador, no caso em tela ao Presidente da República, para que esse opte sempre pela solução mais adequada para atender à finalidade constitucional.

Tanto no estado de defesa quanto no estado de sítio, há a possibilidade do controle político, que poderá ser prévio, concomitante ou sucessivo. Em relação ao controle jurisdicional, tradicionalmente a doutrina entende haver apenas a existência do controle concomitante e o posterior. Por controle concomitante entende-se o acesso ao Poder Judiciário, que não sofrerá nenhum tipo de ataque ou desestabilização durante o estado de exceção, em decorrência do direito fundamental de inafastabilidade de acesso ao Judiciário, previsto no inciso XXXV do artigo $5^{\circ}$ da Constituição da República Federativa do Brasil de 1988.

Retornando ao problema inicial da pesquisa, qual seja, se existe a possibilidade de controle jurisdicional da decretação dos estados de defesa e de sítio e dos atos editados em sua vigência (?), conclui-se que o Poder Judiciário pode controlar quaisquer atos e comportamentos da Administração Pública, desde que o faça para proteger os direitos fundamentais, como também para preservar os valores do Estado Democrático de Direito. A discricionariedade administrativa na verdade constitui um dever e não um poder, como está erroneamente nomeada, o que faz com que deva ser compreendida como o cumprimento do dever de alcançar a finalidade legal. Os princípios do Estado Democrático de Direito, principalmente a proteção dos direitos fundamentais, devem ser respeitados pelo Estado, sob pena de se contrariar uma das mais significativas conquistas da história da humanidade. 


\section{REFERÊNCIAS}

AGRA, Walber de Moura. Curso de direito constitucional. 7. ed. Rio de Janeiro: Forense, 2012.

ALEXY, Robert. Vícios no exercício do poder discricionário. In: DI PIETRO, Maria Sylvia Zanella; SUNDFELD, Carlos Ari (Org). Doutrinas essenciais: direito administrativo. São Paulo: Revista dos Tribunais, 2012, p. 1213-1261.

ARAGÃO, Alexandre Santos de. Curso de direito administrativo. 2. ed. Rio de Janeiro: Forense, 2013.

BACIGALUPO, Mariano. La discrecionalidad administrativa. Madri: Marcial Pons, 1997.

BARROSO, Luís Roberto. Curso de direito constitucional contemporâneo: os conceitos fundamentais e a construção do novo modelo. São Paulo: Saraiva, 2009.

BINENBOJM, Gustavo. Um novo direito administrativo para o século XXI. Revista de Direito da Câmara Municipal do Rio de Janeiro, v. 1, n. 1, 1997.

BRASIL. Constituição (1988) Constituição da república federativa do Brasil. 29. ed. São Paulo: Atlas, 2008.

CANOTILHO, José Joaquim Gomes. Direito constitucional e teoria da constituição. 7. ed. Coimbra: Almedina, 2003.

CASSAGNE, Juan Carlos. Derecho administrativo. 7. ed. Buenos Aires: Abeledo Perrot, 2002. (Tomo 2).

DANTAS, Paulo Roberto de Figueiredo. Curso de direito constitucional. 3. ed. São Paulo: Atlas, 2014.

DI PIETRO, Maria Sylvia Zanella; SUNDFELD, Carlos Ari (Org). Doutrinas essenciais: direito administrativo. São Paulo: Revista dos Tribunais, 2012. 
FERREIRA FILHO, Manoel Gonçalves. Curso de direito constitucional. 40. ed. São Paulo: Saraiva, 2015.

GRAU, Eros Roberto. O direito posto e o direito pressuposto. 7. ed. São Paulo: Malheiros, 2008.

GROTTI, Dinorá Adelaide Musetti. Discricionariedade administrativa. In: DI PIETRO, Maria Sylvia Zanella; SUNDFELD, Carlos Ari (Org). Doutrinas essenciais: direito administrativo. São Paulo: Revista dos Tribunais, 2012, p. 1103-1148.

MASSON, Nathalia. Manual de direito constitucional. 3. ed. Salvador: Juspodivm, 2015.

MEDAUAR, Odete. Direito administrativo moderno. 10. ed. São Paulo: Revista dos Tribunais, 2006.

MEIRELLES, Hely Lopes. Direito administrativo brasileiro. 23. ed. São Paulo: Malheiros, 1998.

MELLO FILHO, José Celso de. Constituição federal anotada. São Paulo: Saraiva, 1984.

MELLO, Celso Antônio Bandeira de. Curso de direito administrativo. 27. ed. São Paulo: Malheiros, 2010, p. 126.

MELLO, Celso Antônio Bandeira de Mello. Discricionariedade e controle jurisdicional. 2. ed. São Paulo: Malheiros, 2010.

MORAES, Humberto Peña. Mecanismos de defesa do estado e das instituições democráticas no sistema constitucional de 1988: estado de defesa e estado de Sítio. Revista da EMERJ, Rio de Janeiro, v. 6, n.23, p. 198-216. 2003.

NOVELINO, Marcelo. Curso de direito constitucional. 11. ed. Salvador: Juspodivm, 2016.

PADILHA, Rodrigo. Direito constitucional. 4. ed. Rio de Janeiro: Forense; São Paulo: Método, 2014. 
SILVA, De Plácido e. Vocabulário jurídico conciso. Rio de Janeiro: Forense, 2008.

SILVA, José Afonso da. Comentário contextual à constituição. 6. ed. São Paulo: Malheiros, 2009.

SUNDFELD, Carlos Ari. Discricionariedade e revogação do ato administrativo. In: DI PIETRO, Maria Sylvia Zanella; SUNDFELD, Carlos Ari (Org). Doutrinas essenciais: direito administrativo. São Paulo: Revista dos Tribunais, 2012, p. 1029-1038.

VALADÉS, Diego. Problemas constitucionales del estado de derecho. 2. ed. Buenos Aires: Astrea, 2011. 